\title{
ANTROPOFAGIA Y DIFERENCIA CULTURAL: CONSTRUCCIÓN RETÓRICA DEL CANÍBAL DEL NUEVO REINO DE GRANADA
}

POR

\author{
Álvaro Félix Bolaños \\ Tulane University
}

\begin{abstract}
Hallaron en una calle una criatura española de hasta diez meses atravesada con tres lanzadas, en otras partes derramados sesos de criaturas que el barbarismo cogía de los pies y daba con ellos en los cimientos de las casas, en que hallaron arroyos de sangre de las mujeres que habían despedazado; sobre las tapias estaban arrojadas las tripas por una parte, vientres por otra, por otra asadura, y en un asador estaban atravesados unos hígados y livianos [sic] de personas medio asadas, con tres bocados dados en ellas, que causaba horror mirarlos.

Noticias historiales de las conquistas de Tierra Firme en las Indias Occidentales. Fray Pedro Simón
\end{abstract}

\section{ANTROPÓFAgos EUROPEOS Y AMERICANOS}

El asesinato y la violencia contra gentes pacíficas, el consumo de la carne de las víctimas (equiparable para muchos a alimentarse de inmundicias), el necesario sacrificio pagano para este consumo, así como el bestial deleite exhibido en él, son todos rasgos temibles y despreciables para la tradición cultural europea que desde la época clásica han servido para caracterizar al "bárbaro", es decir, a aquel "otro" amenazante residente en espacios remotos y no urbanos. Estos rasgos conforman un marco representativo en el que la mayoría de los historiadores europeos colocaron a los indios americanos. ${ }^{1}$

Para los historiadores de una tradición cultural grecolatina que se afianzaba en la expansión imperial de España en América durante el Renacimiento, los nativos americanos se definían señalando en ellos sus carencias de rasgos culturales europeos. La falta de vestidos y de reconocible organización social y familiar para los españoles, los hacía carentes de "policía" (es decir, de orden civil); la falta de alfabeto, los hacía carentes de historia; y la práctica de la antropofagia, de calidad humana. El indio americano es así un engendro sin civilización (lo que lo convierte en bárbaro) y sin rasgos humanos (lo que lo convierte en bestia).

1 Sobre el "bárbaro" como caníbal, véase de Anthony Pagden el capítulo 2, "The Image of the Barbarian", The Fall of Natural Man (Cambridge: Cambridge University Press, 1982). 
El sistema de organización de la información recogida por europeos sobre los pueblos extraños desde las épocas de Heródoto hasta los siglos XVI y XVII ha recurrido siempre a la comparación negativa (implícita o explícita) con la propia cultura del observador. El autor de la crónica o "Relación" siempre tiene en mente un modelo conceptual europeo ante el que la cultura foránea aparece siempre como incompleta o anormal. En otras palabras, la percepción de los rasgos culturales no europeos no se hacía aceptando una "alteridad" (es decir la posibilidad de la diferencia cultural) sino exigiendo una "identidad" (no tolerando lo culturalmente extraño). ${ }^{2}$ Los rasgos culturales no europeos de los indios americanos eran, entonces, para los españoles no solamente asquerosos, sino de perentoria corrección. Tal es el caso del franciscano español, Fray Pedro Simón, autor del texto correspondiente al epígrafe de este trabajo. ${ }^{3}$

¿Qué diferencia de caracterización habría en la narración de actos de violencia y canibalismo cuando los comedores de carne humana son nativos americanos o colonizadores europeos? Para Alvar Núñez Cabeza de Vaca el español llega a comerse a sus congéneres solamente en condiciones de excesivo rigor para la supervivencia y de total colapso del aparato material y cultural que los sustenta: "Y cinco christianos que estavan en rancho en la costa llegaron a tal estremo que se comieron los unos a los otros hasta que quedo uno solo, que por ser solo no huvo quien lo comiese" (53). ${ }^{4}$ Sin embargo, este cristianamente censurable acto, que coloca a los españoles en un grado moral y cultural inferior a los indígenas ("Deste caso se alteraron tanto los indios y ovo entre ellos tan gran escándalo, que sin dubda si al principio ellos lo viera, los mataran" [Cabeza de Vaca, 53]), no lleva a Cabeza de Vaca a realizar en su "Relación" una demonización de estos caníbales.

Igual actitud exhibe Gonzalo Fernández de Oviedo quien, aunque censura acremente el canibalismo de españoles - esta vez sobre indígenas-, su amonestación no sobrepasa la denuncia moralista de atentados de capitanes y soldados contra los preceptos del cristianismo (diez mandamientos, "no matar"; obras de caridad, "enterrar los muertos"; y por supuesto, no profanar cadáveres a dentelladas); tampoco sobrepasa la censura de la correspondiente falta de "policía" necesaria en el fundador de nuevos conglomerados sociales en las Indias. La altiva recriminación moral y civil viene después de la implícita "explicación" (o justificación) del acto antropofágico por el rigor excepcional de las desventuras y el hambre en yermas tierras americanas.

\footnotetext{
${ }^{2}$ Aludo aquí al concepto de construcción cultural de la alteridad del sujeto colonial en los discursos sobre la conquista y colonia españolas en América de Rolena Adorno en "El sujeto colonial y la construcción cultural de la alteridad", Revista de crítica literaria latinoamericana 14, 28 (1988), 55-68. Sobre la etnografia europea desde la época clásica hasta el Renacimiento véase Margaret Hodgen, Early Anthropology in the Sixteenth and Seventeenth Centuries (Philadelphia: University of Philadelphia Press, 1964).

${ }^{3}$ Se trata de Noticias historiales de las conquistas de Tierra Firme en las Indias Occidentales, vol. 6, Juan Friede, editor (Bogotá: Biblioteca Banco Popular, 1981) 379. Véase Noticia 7, cap. 34. Obra escrita más o menos 18 años después de los eventos narrados en este epígrafe -ataque de los indios pijaos a la ciudad de Ibagué, Nuevo Reino de Granada, en 1606 - con información proveída por documentación forense y entrevistas a soldados, testigos y oficiales del gobierno colonial.

${ }^{4}$ La relación o naufragios de Alvar Núñez Cabeza de Vaca, Martín Favata y José Fernández, editores (Potomac, MD: Scripta Humanistica, 1986).
} 
Fernández de Oviedo no recurre a la creación drástica de un "otro" disímil y amenazante para el español. Su texto no ubica al antropófago europeo en una región distinta a la de los españoles, sino en una etérea zona cercana - aunque desaprobada - a la que todo europeo en determinadas condiciones puede arribar: la del pecado y el delito. Narrando la empresa fallida del capitán Iñigo de Vascuña en Venezuela, por ejemplo, Fernández de Oviedo explica cómo por codicia los españoles "cometen cosas inhumanas e inauditas y aborrecidas a los hombres de razón (...) e aquel Cristóbal Martín, escopetero, estaba abriendo un muchacho indio manso (...) al cual mató para comerse (...)". Ante lo cual exclama el cronista: "Yo no puedo creer sino que entre estos pecadores andaba el diablo" (3: 26). Este antropófago europeo, aunque inicuo pecador y delincuente, no abandona familiares instancias culturales o humanas.

¿Cómo se caracteriza al antropófago abominable cuando el relato en cuestión está obligado a establecer límites entre un espacio físico y cultural "nuestro" y correcto (privativo del que se considera "civilizado" y cristiano) y un segundo espacio incorrecto (atribuido a "bárbaros")? Cristóbal Colón, ante la amenazante imagen de un guerrero indígena de las islas del caribe ("el cual diz que era muy disforme en el acatadura" [114]), concluye sin vacilación en su Diario "que devía de ser de los caribes que comen los hombres" (114). ${ }^{6}$ Igualmente el mismo Fernández de Oviedo, en una de las definiciones del indígena de Tierra Firme más popularizadas del siglo XVI, dice cabal e inequívacamente en 1526: "A la parte del levante (...) [los caribes] comen carne humana, y son abominables, sodomitas y crueles, y tiran sus flechas emponzoñadas de yerba" (73). ${ }^{7}$

Por otra parte el "barbarismo" del epígrafe que según Simón ataca un pueblo inerme, asesina y se come mujeres y niños, se encarna en los indios pijaos del Nuevo Reino de Granada quienes son de configuración racial y cultural drásticamente distinta a la europea y provenientes de regiones exóticas y lejanas. Esta distribución de espacios de bondad y error es una operación de clara e indeleble señalización de líneas fronterizas entre lo "nuestro" benigno y lo "extraño" hostil. ${ }^{8}$

Cuando el acusado de canibalismo es un individuo de naturaleza cultural y racial no europea existe una mayor receptividad - de lectores de todas las épocas - y un menor cuestionamiento del texto acusatorio. ${ }^{9}$ Las pruebas con que la historiografia colonial ha

\footnotetext{
${ }^{5}$ Véase Historia general y natural de las Indias, lib. 25, capítulos 6 y 7 (Madrid: Atlas, 1959).

${ }^{6}$ Véase Textos y documentos completos, Consuelo Varela, editor (1982. Madrid: Alianza Editorial, 1984).

${ }^{7}$ Véase capitulo IX, "De las cosas de Tierra-Firme", de Sumario de la natural historia de las Indias, Manuel Ballesteros, editor (Madrid: Historia 16, 1986).

${ }^{8}$ Parto aquí de la idea de Certeau sobre el poder del texto (sobre entidades culturalmente lejanas y disímiles) para componer y distribuir lugares y constituirse en narración de un espacio. "The text accomplishes a spatializing operation which results in the determination or displacement of the boundaries delimiting cultural fields (the familiar vs. the strange). In addition, it reworks the spatial divisions which underline and organize a culture" (67-68). Véase de Michel de Certeau, "Montaigne's 'Of Cannibals': the Savage 'I'," Heterologies. Discourse on the Other (Minneapolis: University of Minnesota Press, 1986).

9 Para Antonio Pigafetta - basado en rumores ("Esto me contó Ioanne Carvagio" [60])—- los indios brasileños: "comen carne humana, la de sus enemigos, no por considerarla buena, sino por costumbre"
} 
fabricado la imagen terrible e imperecedera de un devorador de carne humana son por lo general arbitrarias y, en la mayoría de los casos, palmarias calumnias. Son arbitrarias porque el europeo de los siglos XVI y XVII que estuvo en contacto directo o indirecto con el canibalismo de los indios americanos era, por sus prejuicios culturales y religiosos, el individuo menos indicado para dar razón de tal práctica; ${ }^{10}$ y son calumnias porque, como veremos, se convirtió en un muy conveniente tópico para desacreditar a todos aquellos indígenas que en algún momento $u$ otro tenían que presentarse como esclavizables y destructibles en favor del interés económico y político de los colonos europeos y euroamericanos.

El término "caníbal", acuñado por Cristóbal Colón en 1492, inaugura un concepto de relación con los nativos americanos que supone el ejercicio de una férrea tutoría hispana sobre éstos para su coerción, destrucción de su cultura y usufructo de su trabajo, tierra y riquezas. En otras palabras, inaugura la colonización europea de los americanos. ${ }^{\text {" }}$ Sin embargo, la insistencia de Colón (y otros colonizadores de la época) en la calidad de devorador de hombres del americano rara vez estuvo acompañada de pruebas fehacientes de tal conducta. ${ }^{12}$

En la primera "Instrucción" de la Reina Isabel del 29 de mayo de 1493, por ejemplo, sobre la defensa de los indios como vasallos, se hace la excepción de los caribes: Dice Castañeda al respecto: "solamente aquéllos que se mostrasen rebeldes e insumisos podrían ser esclavizados conforme al derecho de guerra. Y sobre todo los caribes, que, además de no reconocer el dominio español, eran crueles y antropófagos" (115). Una segunda condena de la Reina (en 1501), recuerda la prohibición de esclavizar a los vasallos indios, pero hace

(60). El editor de este texto, Leoncio Cabrero, le agrega a este pasaje una cita "explicativa" a pie de página: "Existencia de costumbres caníbales" (60). Es decir, tanto para el cronista del siglo XVI como para el editor moderno, el canibalismo de los brasileños, a pesar de falta de verificación documental, es un hecho establecido e indiscutible. Véase Antonio Pigafetta, Primer viaje alrededor del mundo, Leoncio Cabrero, editor (Madrid: Historia 16, 1985).

${ }^{10}$ Además el europeo de la época carecía de los medios adecuados para la producción de un documento confiable: "Those observers, because they preceded the advent of an ethnographic tradition, typically did not give much account of the social and cultural context in which institutionalized cannibalism occurred. However factual their reports might be, cannibalism remained for them an object of curiosity" (1). Véase The Ethnography of Cannibalism, Paula Brown y Donald Tuzin, editores (Washington, DC: Society for Psychological Antropology, 1983).

"Sobre este concepto de "caníbal" véase Peter Hulme, Colonial Encounters. Europe and the Native Caribbean, 1492-1797 (London and New York: Methuen, 1986).

${ }^{12}$ Sobre la manipulación del concepto de "caníbal", frecuentemente para aprovecharse de mano de obra indígena, véase Michael Palencia-Roth. "La ley de los caníbales, Cartagena y el Mar Caribe en el siglo XVI", De ficciones y realidades. Perspectivas sobre literatura e historia colombianas, Alvaro Pineda Botero y Raymond Williams, editores (Bogotá: Tercer Mundo Editores, 1989) 123136; Demetrio Ramos, "Actitudes ante los caribes desde su conocimiento indirecto hasta la capitulación de Valladolid de 1520", Estudios sobre política indigenista española en América, Vol. 1 (Valladolid: Seminario de Historia de América, Universidad de Valladolid, 1975) 81-110; Paulino Castañeda, "La política española con los caribes durante el siglo XVI", Homenaje a Ciriaco PérezBustamante, Vol. 2 (Madrid: Instituto Gonzalo Fernández de Oviedo. Consejo Superior de Investigaciones Científicas, 1970) 73-130. 
nuevamente la salvedad de los caribes quienes "están endurecidos en su mal propósito, despedazando e comiendo los dichos indios [amigos]" (Castañeda 115). Con base en esa información la Reina les da licencia ...

e facultad a todos e cualesquiera personas que con mi mando fuesen ..., para que fagan guerra a los caribes ... e los puedan cabtivar e cabtiven, para llevar a las partes e yslas donde quysieren, e porque los puedan vender e aprovecharse dellos sin que por ello caygan nin yncurran en pena alguna" (Casteñaba 115).

De esta excepción, como es de esperarse, fácilmente se abusó, aun contra indios sobre los que no recaía ninguna sospecha de canibalismo. En lo que sigue, y con un ejemplo concreto del siglo XVII en el Nuevo Reino de Granada, trataremos de señalar la maleabilidad de esta operación retórica de demonización de los indios americanos y, por consiguiente, su fácil manipulación en cualquier época y circunstancia histórica.

\section{El caníbal pijao del Nuevo Reino de Granada}

El muy popular Gran libro de la cocina colombiana ${ }^{13}$ considera necesario explicar que los platos típicos de las provincias del Tolima y el Huila (al suroccidente del territorio colombiano).

... comparten su tradición culinaria y algunas especialidades, aunque con matices locales. Sus aborígenes, "los pijaos", de los que quedan muy pocos, han perdido su cocina tradicional, hecho afortunado pues fueron antropófagos. Existen no obstante vestigios de lo que fuera su cocina en el Museo de Armero, representados por mazorcas y cáscaras de plátanos fosilizadas (énfasis nuestro 166).

La sorda ansiedad que revela esta incómoda pero necesaria aclaración -en un libro que aspira a su difusión popular en Colombia hoy- es efecto del perdurable éxito que ha tenido una de las más afortunadas falacias en la historia del encuentro entre colonizadores españoles y los nativos de la región del alto Magdalena en el Nuevo Reino de Granada (hoy Tolima y Huila), en particular, los indios pijaos: aquélla de identificar la antropofagia ritual con su dieta cotidiana. Dos cosas nos aseguran los autores de este libro de cocina: primera, que la culinaria del Tolima y del Huila no tiene vestigios de la afortunadamente ya extinta dieta canibalística pijao (de la cual, curiosamente, no quedaba evidencia arqueológica en el mencionado Museo de Armero); y segunda, que ya no hay muchos aborígenes en el área.

En otras palabras, que tanto la culinaria antropofágica como los cocineros nativos han ya desaparecido $y$, por consiguiente, los suculentos platos que pasan a recomendar no van a darnos sorpresas desagradables. La ironía de este aserto sobre la doble extinción del hábito de alimentarse de carne humana y de los caníbales que la disfrutaban está en el hecho - seguramente no aparente para los autores de este libro de cocina- de que fue aquella indulgente falacia una de las justificaciones principales del brutal exterminio de

${ }^{13}$ Bogotá: Instituto Colombiano de Cultura, Círculo de Lectores, S.A., 1984. 
que fue objeto la nación de los pijaos en el siglo XVII. Tal aserto es también evidencia de que la actitud frente al indígena, de parte de individuos que se consideran civilizados, no ha cambiado en 500 años.

La tenaz resistencia de los indios pijaos a la colonización española desde mediados del siglo XVI tuvo al Nuevo Reino de Granada al borde del colapso a principios del siglo XVII. En 1604 la Corona española nombró al militar Juan de Borja presidente de la Audiencia de Santa Fe con el encargo de la pacificación de los pijaos y otro pueblo rebelde, el de los carare. Combinando iniciativas oficiales y privadas, Borja organizó una campaña de exterminio de varios años que consistió en constantes ataques al territorio pijao por distintos flancos, destrucción sistemática de sus sementeras varias veces al año, ejecución inmediata de prisioneros varones y diseminación de los sobrevivientes en encomiendas como esclavos. Fray Pedro Simón, autor de la historia de la guerra con los pijaos, explica el efecto de esta rigurosa campaña:

Con todo eso se fue continuando la guerra con la fuerza que pedía la necesidad con entradas y salidas de soldados, por los años siguientes de nueve y diez, y aun hasta el de once $[1609,1610,1611]$, hasta que quedaron todas aquellas largas provincias como lo están hoy [Fray Pedro escribe alrededor de 1623-24], sin que se encuentren con tan un solo indio (6: 446). ${ }^{14}$

La ansiedad frente al peligroso indio caníbal, y en particular, la zozobra ante la culinaria de estos indios, han sido tópicos desarrollados desde temprano en la historia de las relaciones entre europeos y nativos en la conquista y la colonia del territorio colombiano. Fray Pedro Simón narra, por ejemplo, el caso de dos españoles hambreados que se encuentran con un cocido de maíz en una casa de estos indios.

Y entre los granos halló uno de los soldados un pedazo de carne, de quien juzgando sólo su apetito con que le comenzó a comer, decía que era tocino. Con lo cual, engolosinado el otro soldado, ahondando más en la olla por si acaso hallaba en ella del tocino que el otro decía, sacó en la totuma una mano entera de persona, por donde echaron todos de ver ser el tocino que decía algún pedazo de carne de la cabeza ... (capítulo 47, noticia 7 de la parte $3,6: 434)$.

En esta magistral narración de Simón, el doblemente macabro descubrimiento de estos furtivos comensales (el del paradero de su compañero perdido, y el de la naturaleza del estofado que seguramente dejaron de consumir en el acto) pone de manifiesto una común reacción ante unos indios considerados indiscutiblemente como desaforados e indiscriminados comedores de carne humana: se trata del temor de terminar en las fauces de este ya catalogado enemigo implacable del género humano, y el de participar

\footnotetext{
14 Véase sobre esta guerra, además de Noticias historiales de Fray Pedro Simón: Juan de Borja, "Guerra de los pijaos" (presentación de carta a Felipe III), transcripción de Ernesto Restrepo Tirado, Boletin de Historia y Antigüedades 14, 159 (1922) 129-164; Juan de Borja, "Guerra con los pijaos" (Carta al Rey Felipe III), transcripción de Ernesto Restrepo Tirado, Boletín de Historia y Antigüedades 14, 158 (1922) 113-115; y de varios autores, "Campaña contra los pijaos en 1603 y 1604", Órgano del Centro de Estudios Históricos de Manizález, 22 (1920) 405-432.
} 
inadvertidamente de su dieta canibalística. Tanto en 1624 en que Fray Pedro escribe esta narración como en nuestra época, en la que hablamos con cautela de la culinaria de la región del Tolima y el Huila en Colombia, tal ansiedad es palpitante.

El tema de la antropofagia de los indios pijaos fue el que más atención recibió entre los cronistas del Nuevo Reino de Granada que se ocuparon de ellos y quienes se unían así a una larga lista de autores que desarrollaron el tópico del caníbal para justificar la reducción militar y la esclavización de los indígenas rebeldes. También fue el que en la Europa del Renacimiento proveyó un material narrativo que frisaba con lo dramático, lo espectacular y lo macabro. Este material le proporcionaba al lector español de la época narraciones exóticas, novedosas, y a veces escandalosas, a la altura de expectativas creadas, entre otros, por los libros de caballerías y los libros de viajes a regiones no europeas. ${ }^{15}$ En este sentido el material etnográfico de los indios del Nuevo Mundo cumplió, entre otras, una función de entretenimiento de un público general que estaba más interesado en curiosidades que en la adquisición de información sistemática. ${ }^{16}$

Las negativas características atribuidas al militarmente irreductible indio pijao del Nuevo Reino de Granada se convirtieron en epítome del nativo de las Indias en la obra que establece las nociones más estereotípicas de ellos: Noticias historiales del ya mencionado franciscano español Fray Pedro Simón. Para este autor hablar de los indios de estas tierras era hablar de "bestiales ritos", "idolatrías", "crueldades", "tiranías," "pecados nefandos" y "carnicerías de carne humana (énfasis nuestro, Prólogo, 1: 92). A Simón le correspondió (por contingencias históricas y personales) escribir la primera narración sistemática de la guerra con estos indios a principios del siglo XVII sintetizando una estructura binaria de pijaos-bestiales vis-a-vis españoles-civilizadores que todavía perdura.

Las referencias a los pijaos hechas por los autores anteriores a Simón (Juan de Castellanos, Fray Antonio Medrano y Fray Pedro Aguado, por ejemplo) siempre fueron marginales en razón precisamente de la todavía para entonces (siglo XVI) marginal importancia que el territorio pijao tenía para la expansión española. El interés de Simón en el tema coincide con la gran atención documental y militar que recibieron los pijaos de parte de los españoles a principios del siglo XVII.

\section{Fabricación Retórica de las "CARnicerías de carne humana"}

Uno de los tópicos más sonados en la caracterización de los pijaos como caníbales es el de las "carnicerías de carne humana", según el cual ellos tenían un centro comercial antropofágico en la llamada "loma de las carnicerías" en la región del antiguo Tolima Grande. Este tópico lo han venido repitiendo autores como José Manuel Groot en 1856, ${ }^{17}$

15 Véase de Rolena Adorno, "Literary Production and Supression: Reading and Writing about Amerindians in Colonial Spanish America", Dispositio 11, 28-29 (1986) 1-25.

${ }^{16}$ Véase de John Rowe, "Ethnography and Ethnology in the Sixteenth Century", The Kroeber Anthropological Societi Papers, 30 (1964) 1-19.

${ }_{17}$ José Manuel Groot, Historia eclesiástica y civil de Nueva Granada, vol. 1 (Bogotá: Ministerio de Educación Nacional, Ediciones de la Revista Bolívar, 1957) 232-33. 
los autores del Handbook of Latin American Indians en 1946, ${ }^{18}$ Herman Trimborn en 1949 -quien, aunque no habla de carnicerías pijao, cree en los mercados de carne humana, ${ }^{19}$ y Manuel Lucena Salmoral en 1966, quien habla de un comercio frecuente en este lugar con despojos humanos. ${ }^{20}$ Ecos de su supuesta existencia se notan en el ya mencionado libro de cocina colombiana de 1984.

La búsqueda de este lugar para destruirlo fue uno de lo pretextos centrales de la invasión del territorio pijao. En lo que sigue examinaremos el origen y la utilización típica de ese tópico de "las carnicerías de carne humana" de los pijaos, que conforma una de las caracterizaciones más exitosas y más culturalmente segregacionistas de la historiografía colonial sobre el caníbal americano. Para ello me referiré tanto a textos considerados históricos como a alguna documentación oficial originada entre los años 1602 y 1604 en relación con poblaciones asediadas y/o atacadas por los pijaos como Cartago, Buga, Ibagué (la ciudad de marras en el epígrafe), etc., situadas a ambas laderas de la Cordillera Central en el suroccidente colombiano, durante la ofensiva más osada y fuerte de los pijaos. ${ }^{21}$ Tal documentación, utilizada entre muchos por Fray Pedro Simón, da por sentada, sin pruebas, la existencia de la antropofagia de estos nativos.

El 5 de noviembre de 1602 - por ejemplo- en la ciudad de Ibagué, el colono Alonso Sánchez, entre otros, testifica su verificación ocular de los daños causados por un ataque de los pijaos en un auto ante el escribano Rodrigo Pérez Navarro. Este auto hará parte de un legajo de documentos forenses que buscan persuadir a la Real Audiencia del peligro que corren pueblos como Ibagué si no se financia la defensa del llamado fuerte de Las Mesas. Alonso Sánchez dice:

... porque este testigo halló en estos dos pueblos [Neiva y la Plata, cercanos a Ibagué] y los vio despoblados de españoles y de los naturales, como están hoy día destruidos y quemados, y vio este testigo carnicería pública de carne humana en tierra de indios pijaos y esta ciudad está en mucho peligro y riesgo de los dichos indios (énfasis nuestro 20).22

\footnotetext{
${ }^{18}$ Handbook of Latin American Indians, vol. 2 (Washington: United States Government Printing Office, 1946). "The Pijao were a particularly cannibalistic people, and they even held public sales of human flesh on a little hill called "Carnicerías"' (958).

${ }^{19}$ Herman Trimborn, Señorío y barbarie en el Valle del Cauca. Estudio sobre la antigua civilización Quimbaya y grupos afines del oeste de Colombia (Madrid: Consejo Superior de Investigaciones Científicas, 1949) 411.

${ }^{20}$ Manuel Lucena Salmoral, Don Juan de Borja. Primer presidente de capa y espada del Nuevo Reino de Granada (Madrid: acultad de Filosofia y Letras, 1966) 108-109.

${ }^{21}$ Son relaciones, autos, declaraciones de testigos, peticiones, etc. presentes en el Archivo Nacional de Colombia y transcritos en publicaciones como Los inconquistables y las del Órgano del Centro de Estudios Históricos de Manizález. Esta documentación es fundamental para cualquier estudio de este conflicto entre colonizadores y nativos. Corresponde a versiones directas - de soldados, capitanes, y oficiales del gobierno, muchos de ellos testigos oculares- de la primera fase de la guerra que despertó la atención de la corona española y del Consejo de Indias. Nunca antes los pijaos habían recibido tan profusa y urgente atención militar y documental.

${ }_{22}$ Los inconquistables. La guerra de los Pijaos 1602-1604, Enrique Ortega Ricaurte, editor (Bogotá: Archivo Nacional de Colombia, Prensas del Ministerio de Educación Nacional, 1949).
} 
Esta declaración de haber "visto" carnicerías de carne humana está en el contexto de testificaciones que deberán enumerar en detalle los daños causados al fuerte. Don Alonso Sánchez, sin embargo, agrega en medio de tal enumeración de daños su supuesta verificación ocular de la existencia de "las carnicerías", ítem que no pertenece ni al tiempo ni al espacio del tema central del auto, es decir, las consecuencias del ataque pijao al fuerte. La impertinencia y el carácter fortuito de esta heterogénea información sobre antropofagia pijao en este auto, sugiere en Alonso Sánchez el deseo de magnificar el peligro que representan estos indios para Ibagué y las haciendas aledañas trayendo a cuento una "evidencia" de la que - a pesar de haber sido testigo ocular, según dice- no ofrece detalle alguno. Eso es extraño si tenemos en cuenta que de lo que se trata en estas declaraciones ante escribano público es, precisamente, de dar detalles para persuadir a la Real Audiencia.

El asunto de las "carnicerías de carne humana" que se les atribuyó a los pijaos se había convertido en un tópico imprescindible en la caracterización de estos indios como bestias. Fray Pedro Aguado, desde 1568 en que le da los últimos toques a su Recopilación historial, hace referencia al famoso sitio: "llega a tanto su maldad que tienen carnicerías públicas de carne humana, donde matan y venden por piezas y postas la carne de los indios e indias que prenden y cautivan" (2: 490) ${ }^{23}$ Aguado no cita testigos ni presenta prueba alguna. Diego de Bocanegra, uno de los veteranos de la guerra contra los pijaos desde la segunda mitad del siglo XVI, por su parte, menciona en una carta relatoria a la real Audiencia de 1603 la existencia del mismo lugar:

En los tiempos pasados, que había gran número y cantidad de indios en los valles de Saldaña, Neiva y su comarca, tenían y usaban los indios pijaos carnicerías públicas de carne humana y se vendían los unos a los otros los cuartos de los indios y muchachos captivos, como entre nosotros los de vaca y ternera; esto es cosa sin duda (Los inconquistables 106).

Bocanegra lo da como un hecho establecido, pero como no tiene pruebas que ofrecer se ve en la necesidad de acudir a su prestigio como informante autorizado diciendo: "esto es cosa sin duda". Es interesante notar, sin embargo, que se refiere a la existencia de este lugar en tiempo pasado, que en ningún momento indica que vio tales "carnicerías", ni cita otros testigos. ${ }^{24}$ Es probable, entonces, que Bocanegra esté citando una creencia común, es decir, rumores popularizados. Por consiguiente, según Bocanegra, ya no existen "carnicerías de carne humana" en 1603, lo cual contradice la versión del testigo Alonso Sánchez quien, supuestamente había estado en el lugar el año anterior.

Hay una diferencia en la calidad de estos testigos que vale la pena destacar para sopesar sus respectivas declaraciones. En el auto de Alonso Sánchez se le menciona a él

\footnotetext{
${ }^{23}$ Fray Pedro Aguado, Recopilación historial, 4 volúmenes, Juan Friede, editor (Bogotá: Empresa Nacional de Publicaciones, 1956).

${ }^{24}$ Alonso Sánchez es uno de los muy pocos testigos que afirman haber visto tal mercado pijao de carne humana. Otros testigos, según Groot, son don Pedro Ordónez Ceballos quien dice: "Vide las carnicerías de carne humana, de que doy fe" y "el padre Zamora, la página 349 de su Historia, dice también que tenían carnicerías públicas de carne humana" (Groot 1: 232-33). Su información, sin embargo, es tan vaga como la de Alonso Sánchez.
} 
simplemente como "morador en esta ciudad" [Ibagué] (19). De haber entrado en el terreno de los pijaos como dijo, ha tenido que ser en calidad de combatiente, pues era entonces zona de guerra. Pero no manifiesta tal cosa y no hay razón para omitir tal condición de haber existido, pues la declaración exige todos los datos posibles sobre el declarante para respaldar la testificación. Es siempre probable que este testigo haya estado - como diceen tierra de pijaos y haya visto lo que consideró ser una "carnicería de carne humana" (lo cual si le damos crédito a Bocanegra ha tenido que ser muchos años antes); pero la omisión de detalles al respecto no deja de ser sospechosa. Bocanegra, en cambio, es un individuo más fidedigno en razón de su larga experiencia como capitán en la guerra contra los pijaos desde que se inició la conquista en esas tierras, es un baquiano del terreno pijao y un gran conocedor de las costumbres y tácticas guerreras de ellos; sin embargo, no se atrevió a decir que vio, con sus propios ojos, tal lugar.

El catorce de abril de 1604, Alonso de Herrera, uno de los muchos capitanes que no tuvo éxito contra los pijaos, hizo otra mención incidental de la reputación de estos indios como vendedores de carne humana en una "Relación" en que le aconseja a la Audiencia cómo salir vencedores en la guerra contra ellos. En esta relación hablaba de su expedición de castigo describiendo la quema de las casas de los pijaos, la tala de sus cultivos y hace recomendaciones sobre el tipo de provisiones, el número de soldados y la estrategia necesarios. Hacia el final del texto, en donde Herrera promete, en tono de cruzado, regresar a la tierra de los pijaos para reanudar los castigos, dice que "hará muy grande servicio a Dios y a V.A. porque se quitará una carnicería pública que tienen de carne humana" ("Campaña ..." 429). ${ }^{25}$

Tenemos aquí, entonces, a otro testigo tan autorizado como Bocanegra para hablar de la tierra de los pijaos y quien admite no haber podido, encontrar el consabido centro comercial canibalístico a pesar de su denodada persecución de estos indios a lo largo y ancho de sus tierras. La poca suerte de Herrera buscando el lugar en 1604 confirma - lo dicho por Bocanegra - que para 1603 no existía tal lugar, si fue que existió en absoluto. Sabemos por el detallado informe sobre los progresos de la guerra contra los pijaos que Juan de Borja (1564-1628) le envió al rey Felipe III el veinte de junio de 1608, que el tal mercado no solamente no existía tampoco para esa época, sino que no hacía parte de sus preocupaciones ni de las de sus capitanes quienes estuvieron muy interesados en la demonización de los pijaos. Borja, cuya campaña de exterminio no dejó lugar del territorio pijao sin recorrer, nada dice del asunto a pesar de que se explaya en su visión de las costumbres antropofágicas de estos nativos (véase Borja, "Guerra ..." 134-135).

Este tópico de las Carnicerías parece ya no significar nada para un autor como Juan Rodríguez Freile (entre 1636 y 1638) a pesar de que en El carnero caracteriza a los ya casi extintos pijaos como "bandada de langostas" y "caribes que comían carne humana" (188). ${ }^{26}$ A pesar de que Freile nos dice que de joven recorrió como soldado la región de los pijaos, y entra en detalles sobre sus costumbres canibalísticas, nada dice de "las carnicerías". Tampoco dice nada al respecto Lucas Fernández de Piedrahíta en 1688 quien, en su intento de corregir las historias anteriores sobre el Nuevo Reino de Granada (las de Gonzalo

${ }_{25}$ "Campaña contra los pijaos en 1603 y 1604", Órgano del Centro de Estudios Históricos de Manizález, 22 (1920) 405-432.

${ }^{26}$ Juan Rodríguez Freile, El carnero (Bogotá: Librería Colombiana, 1934). 
Jiménez de Quesada, Juan de Castellanos, Fray Antonio Medrano, Fray Pedro Aguado y Fray Pedro Simón), retoma el tema indígena en detalle, incluyendo los pijaos hasta el año de $1573 .{ }^{27} \mathrm{Al}$ igual que Freile, Piedrahíta trae a cuento los rasgos más popularizados de estos indios incluyendo su valentía y fortaleza, su idolatría y sus sacrificios humanos. Es importante notar que para esta época Piedrahíta no solamente no hace referencia a "las Carnicerías" sino que el canibalismo mismo es algo que merece poca atención. Sólo lo menciona de paso, como dándolo por sentado, pero sin caer en la escandalización mojigata de los testigos antes mencionados o del mismo Fray Pedro Simón.

¿Existió, o no, en territorio de los pijaos-hoy los departamentos de Tolima y Huila en Colombia - un expendio comercial de carne humana? La documentación española y criolla disponible, muy a su pesar, no logra demostrar que sí. ¿Fue acaso una quimera similar a la de El Dorado? ¿O una descarada difamación? Ambas cosas son posibles. Sin embargo, hay un aspecto de la relación de Diego Bocanegra que da cierta luz sobre la posible naturaleza de aquello que propició la creencia y su manipulación. Según Bocanegra, los trozos que se vendían "unos a otros" en esta carnicería eran "cuartos de los indios y muchachos captivos" (106). Esto de los "muchachos captivos" sugiere que pudo haber sido un lugar donde se realizaban sacrificios humanos y canibalismo ritual.

Según el "Epítome de la conquista del Nuevo Reino de Granada", a veces atribuido a Gonzalo Jiménez de Quesada, los Muiscas sacrificaban jóvenes en ceremonias solemnes, aunque no hay en él evidencia del consumo de su carne. ${ }^{28}$

... tienen unos saçerdotes mochachos para sus tenplos. Cada caçique tiene uno y pocos tienen dos, porque les qüestan muy caros, que los conpran por rrescate en grandísimo preçio. Llámanles a estos moxas. Van los indios a comprallos a una probinçia questará treinta leguas del Nuebo Reino, que llaman la Casa del Sol, donde se crian estos niños Mojas (....) Q[uan]do estos llegan a hedad que les paresçe que pueden ser potentes para tocar a muger, matanlos en los templos [córtanles la cabeza] y sacrifican con su sangre a los ydolos (Ramos, Ximénez 299).

Sabemos también, por Pedro Cieza de León y Pascual de Andagoya que, al menos en el valle del río Cauca en el Occidente del hoy territorio colombiano, los españoles encontraron lugares en los que se exhibían, con propósitos rituales, los cuerpos y los trozos embalsamados de enemigos vencidos en guerra. Hablándonos de Petecuy — "el más poderoso de todos sus comarcanos, y a quien todos tenían más respeto" (150)- Cieza describe en detalle uno de estos sitios:

En medio deste pueblo está una gran casa de madera muy alta y redonda, con una puerta en medio; en lo alto della había cuatro ventanas, por donde entraba claridad; la cobertura era de paja; así como entraban dentro, estaba en alto una larga tabla, la cual la travesaba

\footnotetext{
${ }^{27}$ Véase Noticia historial de las conquistas del Nuevo Reino de Granada, 2 volúmenes (Bogotá: Ediciones de la Revista Ximénez de Quesada, Editorial Kelly, 1973).

${ }^{28}$ Véase Demetrio Ramos Pérez, Ximénez de Quesada en su relación con los cronistas y el epítome de la conquista del Nuevo Reino de Granada (Sevilla: Escuela de Estudios Hispanoamericanos de Sevilla, 1972).
} 
de una parte a otra, y encima della estaban puestos por orden muchos cuerpos de hombres muertos de los que habían vencido y presos en las guerras, todos abiertos; y abríanlos con cuchillos de pedernal y los desollaban, y después de haber comido la carne henchían los cuerpos de ceniza y hacíanles rostros de cera con sus propias cabezas, poníanlos en la tabla de tal manera que parescían hombres vivos. En las manos a unos les ponían dardos y a otros lanzas y a otros macanas (capítulo $28,150-151$ ). ${ }^{29}$

Y además de cuerpos embalsamados, agrega Cieza, "había mucha cantidad de manos y pies colgados en el bohío, y en otro que estaba junto a él estaban grande número de muertos y cabezas y osamenta" (151). ${ }^{30}$

Es posible que lo que el testigo Alonso Sánchez y el capitán Diego Bocanegra identificaron con un mercado de carne humana (que ellos nunca vieron) haya sido uno de estos sitios en las que el solemne sacrificio de las víctimas y el posible consumo de su carne estén unidos a un ritual de guerra. En otras palabras, es posible que lo que los españoles identificaron con un lugar de mercadeo de carne humana, es decir, con la famosa "Carnicería", no haya sido otra cosa que un muy peculiar santuario en una zona de conflictos bélicos. Así parece haber pensado Andagoya (quien escribe casi sesenta años antes que estos luchadores contra los pijaos) al concluir su descripción sobre el santuario de Petecuy: "y a éstos que así prendían y mataban, los comían la gente de guerra por victoria" (Andagoya 139).

Armand Labbé, en su estudio sobre la Colombia precolombina, dice en relación con los indios del territorio del Nuevo Reino de Granada: "the hanging of hands and feet may actually have been a reverential act, from the perspective of the indigene" (46); ${ }^{31} \mathrm{y}$ en relación con los pijaos, Labbé agrega: "In other cases, as is recorded for the fierce pijao Indians of the upper Magdalena valley, there appears to have been a distinct and deliberate cult of dominance exercised over the bodies of slain enemies" (46).

La reacción de los españoles ante este tipo de exhibición es, comprensiblemente, de disgusto, aversión y horror, lo cual era precisamente el efecto que los indios querían producir en los forasteros con tal despliegue macabro: "era espantoso verlo, contemplando tan triste espectáculo" (151), nos dice Cieza. Este horror producido en los españoles les facilitaba a los autores de Relaciones y a los cronistas que después componían la historia de la región respectiva no sólo la atribución de inhumanidad a los indios que practicaban tales sacrificios, sino también la caricaturización del acto identificándolo con la base de una economía doméstica. ${ }^{32}$

${ }^{29}$ Pedro Cieza de León, La crónica del Perú, Manuel Ballesteros, editor (Madrid: Historia 16, 1984).

${ }^{30}$ Pascual de Andagoya en su "Relación que da el Adelantado de Andagoya ..." sobre la misma región (occidente colombiano) describe, aunque en menor detalle, el mismo santuario en el que ve "cuatrocientos hombres o los que cabían en aquella sala, desollados y llenos de ceniza, y sin que les faltase figura humana" (139). Véase Relación y documentos, Adrián Blázquez, editor (Madrid: Historia 16, 1986).

${ }^{31}$ Armand Labbé, Colombia before Columbus. The People, Culture, and Ceramic Art of Prehispanic Colombia (New York: Rizzoli International Publications, Inc., 1986).

${ }^{32}$ Una de las elaboraciones "pseudo-etnográficas" en relación con el canibalismo del indio pijao como vicio que satisfacía la economía doméstica, la ofrece Víctor Bedoya en 1950. Según él, los 
Según Cieza la víctimas habían sido "comidos como si fueran animales campestres" (énfasis nuestro 151). La comparación que hace Cieza entre estos despojos humanos con carne de caza para consumo cotidiano, "animales campestres", es típica. Recuérdese la comparación que hace Bocanegra de los miembros cercenados "como entre nosotros los de vaca y ternera" (106). Allí hay una reducción del ritual guerrero y canibalístico a la actividad comercial, o a la modalidad culinaria. Rodríguez Freile hace la misma reducción al hablar de los "duhos y bahaduhos, que estas naciones eran la carne de monte de los pijaos, que salían a caza de ellos como acá se sale a caza de venados" (189). Es ese proceso de caricaturización en la descripción de rasgos culturales no europeos censurados lo que, a nuestro modo de ver, dio lugar a la manipulación del tópico de las carnicerías de carne humana.

\section{CONCLUSIÓN}

Siendo el sacrificio de los enemigos españoles capturados, y el subsiguiente consumo ceremonial de su carne, actos realizados en el contexto de una guerra en que los indios pijaos defendían su terreno invadido, y no una simple satisfacción de una voracidad bestial americana por carne humana, los temores expresados por los cronistas e historiadores del Nuevo Reino de Granada adquieren ante nosotros un significado distinto al que decididamente se proponen en sus relaciones y sus crónicas. Es decir, el temor de ser capturado, sacrificado y comido por los indios es una consecuencia drástica, pero lógica, de cualquier soldado o colono español invasor que pierde en contienda contra los invadidos pijaos. No es, entonces, una expresión natural del barbarismo y la bestialidad que para el europeo de la época supuestamente caracterizaba a la entidades culturales no europeas.

Por otra parte, aquella sorda ansiedad de los autores del consabido libro de cocina colombiana al hablar de los platos típicos del Tolima y el Huila es innecesaria, no porque la antropofagia de los pijaos haya sido imposible, sino porque ésta como acto reverencial y extraordinario, nada tenía que ver con sus hábitos de alimentación cotidianos. Esta desdeñosa actitud cultural, como heredera de una historiografía colonial diseñada para justificar la presencia española en tierra invadidas, parte del supuesto de que lo indígena es erróneo y por tanto carente del derecho a existir. Por eso con alivio pueden declarar como hechos afortunados no solamente que los pijaos han perdido su cocina tradicional - según ellos- antropofágica, sino también que de estos aborígenes quedan hoy muy pocos. Lo primero, como dijimos, es una falacia por mucho tiempo ya privilegiada. Lo segundo es una triste realidad que mucho le debe a esa falacia todavía necesaria en la escritura de la historia del encuentro entre europeos y americanos.

pijaos precipitaban guerras con sus vecinos cuando se les vaciaban las despensas de sus cocinas. Esto da ocasión a una de las más deplorables y denigrantes fantasías históricas sobre la antropofagia americana: "Para ello se reunían las mujeres y los niños en los lugares comunes de mercado, mientras los hombres ocultos en los bosques cercanos esperaban el fin del mercado, disponiéndose para la refriega. Terminado aquél, las mujeres y los niños se retiraban a prudente distancia, y los combatientes entraban en batalla (...) Detrás de los hombres iban las mujeres y los niños recogiendo los muertos y los heridos graves, para llevarlos a sus campamentos y establecer sus carnicerías macabras (3738). Véase Víctor Bedoya, Pijaos y Quimbayas. Etnología y conquistas del Tolima y la hova del Quindio (Ibagué: [sin editorial], 1950). 
